\title{
GENDER IN ONLINE WORLDS: An Introduction to, and Summary of, Cybermind Research
}

\author{
Transforming Cultures eJ ournal, \\ Vol. 2 No 2, December 2007 \\ http:// epress.lib.uts.edu.au/journals/TfC
}

\section{Jonathan Paul Marshall}

\section{Introduction}

This issue of the Transforming Cultures eJournal concludes the publications arising from an Australian Research Council grant exploring the effects of gender online. I take this introduction as opportunity to introduce the other papers and to summarise my previous research. There is no intention to give a general literature review of research into online gender as I have done this on two previous occasions ${ }^{1}$ and several of the other papers in this journal give partial literature reviews.

The primary objective of this journal issue is to compile a collection of writings that present a multi-voiced ethnography of the internet Mailing List 'Cybermind' and its members focusing on issues of gender. The authors wish to explore how issues of gender might be generated and interpreted by List members, and to observe how gender affects List member's interaction with each other in daily online life and in the intersection of the online with their offline and offlist lives. We also aim to investigate how, or if, existing offline factors influence these issues.

All the contributors aim to take advantage of the electronic format to present longer papers than might be customary in print, and to alter papers in response to further ideas or comments from List members or others. As a result, each paper will have a version number, starting with 'Version 1.0'. Changes, and the reasons for those changes, will be

\footnotetext{
${ }^{1}$ Jonathan Marshall "Online Life and Gender Dynamics”, "Online Life and Gender Vagueness and Impersonation", "Online Life and Netsex or Cybersex", and "Online Life and Online Bodies", in Elieen M Trauth (ed) Encyclopedia of Gender and Information Technology, Idea Group, 2006a: 926-51. "Gender in Online Communications" in D. Leu, M. Knobel, C. Lankshear, \& J. Coiro (Eds.), Handbook of Research on New Literacies, Erlbaum 2007a: 495-523.
} 
noted in the 'Comments' section. This section will also store any ongoing discussions or responses to the journal, to allow academics and members of Cybermind to criticise or add their remarks to the contents. Hopefully this will make the journal of ongoing value to readers, and it will make correspondence about the issue easier to track. As a general editorial policy the Transforming Cultures editorial committee allows the journal to publish not only standard refereed articles but articles classed as 'reflections'. These latter articles are included to allow the retelling of personal experience, without having to have academic justification, and to increase the availability of thoughts and controversies from the ground, from people who might otherwise go unheard or who might not have the time to go through rigorous reviewing processes. It also allows the presentation of more 'data' than might otherwise be possible. It is our view that this increases the value of the Journal and the more formal academic writings which are included.

This journal's focus on the one Mailing List counters the tendency of internet research to be scattered. Our research does not compare radically different groups so that we have no idea whether the reported findings are the results of a specific history, of a particular structure of communication, result from the bias of a particular observer, or are contingent upon the week the observer was present. Furthermore we do not take up an isolated or disconnected standpoint: not only do we assume that the List members have interesting and insightful things to say, but all of the authors have at some time, been long term members of Cybermind, able to draw upon lengthy experience of the List. Having different writers participate allows a range of alternate views and accounts of life, which gives a depth to the account of gender unachievable with a single authorial voice, even if we disagree with each other. Our focus also makes it explicit that this is a study of a particular group, not a universal study of internet usage making over-easy generalisations. The authors are specifically discussing internet usage in the Western English Speaking World and largely intellectual middle class usage at that. The authors also consider internet usage as they have found it to be, rather than hiding behind a discourse of futurity in which we discuss what life on the Net might become as if it already occurred. Here we are more realistic, even if it means we could be out of date already. 
Within these historical and ethnographic localisations, nearly all the essays make two points emphatically. The first is that online life is not divorced from offline life, they interact in a multiplicity of ways and the ambivalences of their interaction are a vital part of the phenomenology of 'virtual life'. The second and related point is that online life is in some ways fundamentally, and overtly, ambiguous and uncertain. That we cannot guarantee everything we write about the people involved or their intentions is not simply a failing of research method but is a basic phenomenon of online life itself, which people deal with in various, socially specific, ways, some of which are touched on below.

\section{Introduction to Cybermind}

Cybermind is an internet mailing List which was founded in mid 1994 by Alan Sondheim and Michael Current to discuss "the philosophical and psychological implications of subjectivity in cyberspace" ${ }^{2}$. List members are primarily US-American, British and Australian, but active List members have posted from Europe, Canada, New Zealand, India, South America and the United Arab Emirates. Members generally had access to the internet from both home and work, so the question of the effect of different sites of access on usage was generally not relevant. By far the majority of members could be classified as 'middle-class intellectuals' with good education, but often relatively insecure incomes or career paths.

Since the List's beginning, List members have mixed discussion of the official List topics with dialogue about their personal lives, politics, religion, sex and almost any other subject which arose. Community building and mutual support has been as important, and often more important, than the official topic. Although this can make the List frustrating for those who only wish to discuss the official issues, it makes the List unusually viable as a site for study, as more information and background about members is available than is customary for such forums. List members have also been more than hospitable to ongoing social research, when that research has been open, and the researchers have engaged with the List. The only List wide hostility ever recorded to a researcher was when that researcher appeared at the end of the research, to announce

\footnotetext{
2 The Manifesto is quoted in full in Jonathan Marshall Living on Cybermind: Categories Communication and Control, NY, Peter Lang 2007b. That book also gives a detailed background, history and ethnography of the List.
} 
the fact that they had been researching the List for the last couple of weeks and would now say goodbye and write their report.

All the research reported in this journal has grown out of participant observation, interaction, formal surveys, discussion, putting forward observations for refutation and so on. In my own case I have been on the List since December 1994 until the present day, with occasional periods of quiescence due to illness, or to the necessity of finishing work, and have been formally and openly studying the List since mid 1995. All of the other authors in this Journal issue have spent at least one year on the List at various times, so that even what might appear as their most subjective expressions of opinion are based upon a summary of their experience and give a sample of the kinds of opinions and experiences which might be found on that List. The Project has also been openly discussed on the List and makes use of member's comments.

Men are the dominant gender on the List in terms of their number as subscribers, and in terms of the number of posts they make, yet Cybermind is interesting for the study of gender online, as from the time of its inception until about 2002-3 (when argument about the oncoming Iraq war altered the List), it not only had a highly visible female membership, who generally posted in proportion to their numbers, but also women would frequently remark that it was a relatively female friendly 'place', in which it was generally possible to talk without being attacked, harassed, or excluded, for being a woman $^{3}$. There were always women amongst the highest status and most voluble, posters, again in proportion to the numbers of women subscribed or participating ${ }^{4}$.

This is not to say that it would not be possible to find innumerable examples of sexism and discrimination, and many of the papers in this journal discuss such examples, but that to the contrary of what is stated to be the norm in many studies of online gender, the gender balance and behaviour on Cybermind seemed praiseworthy to the majority of its members. To some extent the papers in this journal attempt to explain both why this should have been and what were the kinds of forces that eventually disrupted the group

\footnotetext{
${ }^{3}$ Women have both written this to the List in general and to me in private. See also Ghaly's paper in this journal.

${ }^{4}$ Data for the changing gender distribution on Cybermind, and the proportion of mail from either gender, is given in the Appendix to Marshall (2007b), and in Alexanne Don's paper in this collection. Over time, very few participants were not 'genderable'.
} 
as a whole, while looking to see what kinds of structures, ideologies and formations influence processes around online gender.

\section{'Gender' and Gender Theory in the Modern World}

Gender online is a complex issue. At the least: it involves: the special features of life online; the importation and modification of offline gender behaviour; and the ways that contexts of gender in the offline world influence our activities and our access to online worlds. It also involves issues of power, subversion of power, communication, miscommunication, categorisation (how people decide what gender, or kind of person someone is, and what gendered properties are relevant in a situation), relationship, exchange, intimacy, privacy, self-identity, group identity, identity of others and so on.

Academic theory is not separate from the lives of the Western middle class and theory about gender is no exception. It informs both the ways we as 'investigators' perceived gender and ourselves, and the ways that List members saw gender and themselves. With this recognition, the whole process of research becomes involved and reflexive. We cannot pretend to take a point outside the dialogue, and the arguments, which take place amongst those we write about. Nor can we take a point outside of gender, no matter how unusual our own gender position is, because this self-position, and selfcategorisation, has taken shape within, and in reaction to, the social environment we write about and write in. However, we can suggest that gender seems to be both an emergent and ongoing process, and an institution ${ }^{5}$. Its experiential form takes shape in our interactions, whilst it is also constituted in a set of social and self-categories which allocate social positions, and reproduce organisational structure. In a way, we live in a world conceived of as 'ideal types'.

All social categories convey information about other people, including their place within the social stratification. By knowing the appropriate categories a person gains considerable knowledge about how they should behave, what they can expect, how wary they should be, how much they might have in common, what kind of projects might be pursued together, how to resolve communication, and so on $^{6}$. In the West

\footnotetext{
${ }^{5}$ Judith Lorber Paradoxes of Gender, Yale UP, 1994: 32ff.

${ }^{6}$ This information may be completely unconscious and incorrect. When a computer was given a gendered voice in a series of experiments, then both sexes took evaluations from male voiced computers more seriously than evaluations from female voiced computers. Female voiced computers which made
} 
these classifications involve, or mask, issues of the ratios of power, subversion, separation of social fields, kinds of knowledge or experience, relationship, exchange, intimacy, privacy, self-identity, group identity, ethos and so on. Western theories about gender particularly intersect with theories and conventions about biology and sexuality and, hence, about the nature of reality ${ }^{7}$.

Because gender serves these quite massive social and cognitive functions offline, people almost inevitably bring their gender expectations with them and take online misgenderings, or uncertainties, simply as those mistakes and uncertainties which happen online, but which do not negate their offline 'reality'. The offline will, as we will show, be taken to confirm or deny online claims ${ }^{8}$. Therefore, there is no necessity for people to discover their ideas about online gender are constrained or relative, although this may happen. On Cybermind, people who had open attitudes to gender seemed to have them before they encountered the List.

Gender is also reinforced as it connects with, or is present in, everything and it cannot be isolated. However, rather than seeing all these other factors as always equally present, it can be preferable, as Laurie wrote to Cybermind (17 Oct.01):

to see gender, race, class, ability, sexual orientation, ethnicity, etc. as configured aspects of life that [...] at any given time may move to the fore to explain the circumstances a person is dealing with.

Members of a gender category, thus, do not necessarily form a uniform group with similar interests and problems. As Rowena agued in a post to the List (7 Oct.01), gender can be cut across by race, wealth, work, religion, nationality categories (and so forth) and people of different genders but of similar culture may have more in common than people of different cultures but similar genders. As analysts, we also cannot assume that

evaluations were considered less friendly than male voiced computers making identical evaluations. Participants denied being influenced by gender stereotypes. B. Reeves \& C. Nass, The Media Equation: How People Treat Computers, Television and New Media Like Real People and Places, Cambridge University Press 1996: Chapter 14.

${ }^{7}$ Gender may well involve issues of biology, but not only is this interaction not well understood, but the research is usually conducted by people with little cross-cultural knowledge of gender behaviour. However, many aspects associated with gender may function like height, which is differentially distributed by biological sex. We cannot guarantee that any individual man will be taller than any individual woman, but in general people make that assumption as part of their ways of organising gender categories, so that if it is found not to be the case people may try and make it so. In a way gender is a matter of expectations interacting with events.

${ }^{8}$ This is discussed below under 'problems of research' and again in my paper in the 'Reflections' section: “Cybermind discusses Gender”, see especially the section on Gender Uncertainty. 
each member of a gender category is the same as all others in every way. Likewise we cannot assume that the ways in which status accrues to people because of their gender is the same across groups, or shares the same status attributes with other genders. Ideas about gender can vary through the group and with situations, as this implies, and definitions can be contested, again within different situations. People do not have to agree with the values, properties and prototypes which are attributed to their gender category by others, and they may contest these valuations, properties prototypes, or they may manipulate them. People may also use their gender to claim privileged access to a culture, or a status, via the categories given to their body, or refuse it to others.

These issues, or the effectiveness of strategies, cannot be decided beforehand, and must be investigated. Thus we concentrate on how gender is used, how differences or similarities are produced, how interdependencies are produced, and how this is affected by the politics of culture and the dynamics of groups which merge, separate and make comparisons, depending on what the contexts.

I thus suggest that gender is an important subsector of category based group dynamics, and follows general principles. The theory of gender deployed in my work arises from the category based theory described in the book Living on Cybermind ${ }^{9}$. Because 'gender' is an instance of a social category in a specific social configuration, there is no need to try and construct a universal definition of gender. Gender may differ in different cultures. In the Western English Speaking World, the primary social definition of gender today seems to have to do with a person's genitalia and the way they are used ${ }^{10}$. This definition grounds a whole series of roles and expectations, which then have little or nothing to do with those genitalia or their use. The difficulties arising from a universal application of the common distinction between sex and gender are well known, and hinge on the fact that the two are not constructed independently in the West, and that the distinction tends to direct attention away from both the differences within the genders, and from the relations between people ${ }^{11}$.

\footnotetext{
9 Marshall (2007b). See also Jonathan Marshall “Categories, Gender and Online Community”, ELearning, 3(2), 2006b. <http://www.wwwords.co.uk/elea/content/pdfs/3/issue3_2.asp\#10>

${ }^{10}$ Lorber (1994: 86). As Lorber points out it is really the presence of male genitals which is decisive.

${ }^{11}$ R.W. Connell, Gender, Polity Press, Oxford, 2002: 7-9.
} 
Social and self categories are not bloodless, and people can gain pleasure from performing/embracing their gender; this may involve using props and tools which then shape the user, as the tools are not separate from the user and their ways of being able to act or express themselves ${ }^{12}$. The tools are also part of a web of reinforcing associations, which makes them disappear (as tools) and seem to be part of the nature of reality. Thus it is impossible to simply be oneself, even though that is often required by Western conventions of authenticity - being oneself has to be indicated through social convention. Similarly, people generally do not invent the self-categories they work with; these categories come from others, and fitting into them, or being fitted into them by others, has consequences. It becomes a question both of what people do with gender and what gender does to them. The more a person approximates the ideal prototype(s) for their gender the higher their status. This status may have costs, and it may activate hostility from out-groups, as well as provide security in in-groups, but both are reinforcing of the values of that category.

The fact that gender is both a category and an institution means that words and rhetoric about that category are never neutral. A personal insult or abuse, an image, or association can become general and part of a continuing culture. Being put into a category, or having that category being given unpleasant associations can lead to physical injury, or to the reception of contempt, or the expectation of obligation without a perceived adequate recompense. Rhetoric, even more so online, is a prime tool of both social control, resistance and the construction of those patterns of action which show power and exclusion in action.

Paradoxically the relevance of gender may vary with different contexts, while it also provides a context itself. The times of salience need to be explored. I have, for example, argued that gender distinction is easily invoked in the shifting and unstable categories of public and private, which are used to frame behaviour, especially to distinguish between intimacy, and exposure, or between types of relationship. It seems males are still associated with the public world and females with the private/intimate world ${ }^{13}$. In a way public and private define gender while gender defines them. Asserting that the

\footnotetext{
${ }^{12}$ Lousie J. Kaplan, Female Perversions, Pandora, London 1991.

${ }^{13}$ Annette Triebel "The Changing Balance of Power between Men and Women: A Figurational Study of the Public and Private Spheres in Western Society” in Thomas Salumets (ed.) Norbert Elias and Human Interdependencies, McGill-Queens University Press, Quebec, 2001: 175-90.
} 
oppositions are structural, if shifting, and not just conceptual, we can perhaps group them as follows:

Public

Dominant

Pragmatic

State Politics or Business

Physical or intellectual Labour

Aggression

Fitness

Male

\section{Intimate}

Secondary

Generous

Domesticity or seclusion

Emotional Labour

Receptivity or placation

Illness, weakness, juvenility

Female

These divisions seem to have particular effects online, as online groups constitute another form of support and contact making, professional and personal - although the support they offer can be limited. Construction of a private and intimate world online, has become the way people attempt to deal with the vagaries of an alienated and isolated public offline world, and this almost automatically involves gender ${ }^{14}$.

To give an example of a response to the onlist as public and the offlist as private, a female list member wrote to me, that:

Net romance, or more generally flirting, usually occurs offlist for me anyway. And it leads me to wonder about this separation. Why do people feel so embarrassed when their private exchanges make it to the wrong destination? One time I almost sent a message intended for $M$ to Cybermind. I was all panicky for a minute until I clicked on cancel; luckily the network was slow and it did cancel. There was nothing in there but some horsing around and the like, but what got to me was the sense that I was going to be "exposed" somehow: it's really hard to dissect my feelings/thoughts about that. I can also remember that one time a very personal message from an academic having health problems made it to a list I was on: the woman quickly sent another post urging people to ignore the previous one, which probably drew more attention to her error.

One important aspect of this public and intimate division is that it is easily crossed by accident and is deeply ambiguous, and thus cannot be resolved simply. Private and public are not fixed categories; the private or intimate realm does not have to be without politics which affect the public domain; nor does the private have to be autonomous

\footnotetext{
${ }^{14}$ Marshall (2007b: 22, 70-72, 106-111 and passim).
} 
from the public; nor does the intimate have to be non-violent in reality (even if it is ideally in ideology) and; neither do these divisions have to be categories or methods of framing discourse which are found everywhere in the world. They do, however, provide the informal institutional backing for Western gender roles.

The view about gender being proposed here, argues that gender both enables, and restricts, behaviour - it is neither merely positive nor merely negative, although it could be predominantly one or the other. Gender can be seen as essential, innate or natural, and it can be seen as an 'addition' to something else. Thus many List members assumed there were significant differences between male and female styles of communication, while others could assume that gender could signify nothing of any importance; although, if neutrality implies maleness, that attitude may act as an attempt to remove challenges based upon those other ideas of gender difference. We might suggest that one paradox around gender in the modern West is that gender is perceived as something which is both immutable and which should have no social effect. Thus men and women should behave differently, but differences in power, remuneration, or social activity are entirely the fault of those who suffer from them.

Distribution of power is also complex and, whatever the official view, it cannot be assumed that men posses all of the power in a society, or that women do not subvert, or avoid that power, or are without powers of their own, or are never dominant. Power appears within a set of dynamic ratios between people and groups as argued by Norbert Elias and is not a thing which is possessed and brought to bear on the unresisting ${ }^{15}$. Even an absolute monarch faces limits of resistance. Such a proposition does not deny that, by all kind of measures, most men may be better off than most women, but that we should not assume that the 'subordinate' is powerless, or without any choice ${ }^{16}$.

\footnotetext{
${ }^{15}$ Norbert Elias What is Sociology?, Columbia UP, 1978: 74ff.

16 Rosi Braidotti in an interview with Judith Butler ("Feminism by any other name", differences: A Journal of Feminist Cultural Studies, 6(2-3) 1994: 27-35), argues that:
}

the focus on gender rather than sexual difference presumes that men and women are constituted in symmetrical ways. But this misses the feminist point about masculine dominance. In such a system, the masculine and the feminine are in a structurally dissymmetrical position: men, as the empirical referent of the masculine, cannot be said to have a gender; rather, they are expected to carry the Phallus - which is something different.

I am not arguing in favour of 'symmetry' merely that 'men' and 'women' are not categorised apart from each other (and other factors), and that although power ratios are unbalanced, it is rare that any social being is without some kind of power. 
Similarly, even if in most societies women appear to be subordinate, there is nothing universal which arises from this unequal balance. As Martin K Whyte argues:

there is no coherent concept of the status of women that can be identified cross-culturally, and that when we think we are looking at aspects or indicators of the status of women we are dealing with essentially unrelated things ${ }^{17}$.

Therefore, the local creation and maintenance of this difference of statuses and roles, and its relation to other differences, has to be investigated rather than assumed.

It also seems that gender categories in the West tend to be binary, and tend to be seen as oppositions. As Mascia-Lees and Black write:

The fact that researchers in many Western countries choose to focus on the differences between men and women, rather than the similarities is itself a product of the history, social and political agenda of these societies... [S]uggesting that gender similarities might be as significant and interesting an area of research as gender differences, strikes most people as absurd ${ }^{18}$.

Those who appear to mix properties from either side of the binary tend to be the subject of suspicion outside their own groups, and further tend to be seen as either one thing or the other. Thus in the West, with heterosexuality as a gender norm, gay men seem to be seen as 'effeminate', or as best hybrid mixtures by others, or possibly as hypermasculine by themselves, rather than as another gender ${ }^{19}$.

Binary gender also becomes paradoxical or dislocating when it is treated as if it was an opposition (as in the formulation of 'the opposite sex') rather than as a difference. Thus if we assume that women and men are logical opposites and thus that women are notmen, and vice versa, then we effectively delete the areas of commonality from our experience and leaving us incomplete. We are simply defining by negation and creating

\footnotetext{
${ }^{17}$ Martin K. Whyte The Status of Women in Preindustrial Societies, Princeton University Press, 1978: 170. Similarly, Michelle Rosaldo argues "male dominance, though apparently universal, does not in actual behavioral terms, assume a universal content or universal shape" ("The Use and Abuse of Anthropology: Reflections on Feminism and Cross-Cultural Understanding”, Signs 5(3), 1980: 389-417: 394). Rosaldo also points out that while she knows of " no case where men are required to serve as an obligatory audience to female ritual or political performance" (ibid: 395), this must be understood in social terms rather than pseudo-biological terms.

${ }^{18}$ Frances E. Mascia-Leas \& Nancy Johnson Black, Gender and Anthropology, Waveland Press, Illinois, 2000: 18.

${ }^{19}$ For a discussion of some of the complexities of 'non-standard' genders throughout the world see Serena Nanda Gender Diversity: Crosscultural Variations, Waveland Press, Illinois, 1999. Particularly relevant is the chapter on how Thai conceptions of kathoey, have changed under the influence of Western gender polarities.
} 
a gendered emptiness and inarticulateness ${ }^{20}$, which may then have social and conceptual consequences, such as people needing to force their completeness through consumption, dominance, pairing, or through imposing particular unrepresentability on the 'other' or on themselves, etc.

The most pronounced gender paradox which emerges, either in discussions on the List, or through this very research, is that drawing attention to gender is fraught and may increase frictions around gender. As Joan Wallach Scott argues in another context:

To the extent that it acted for 'women' feminism produced the 'sexual difference' it sought to eliminate. This paradox - the need both to accept and to refuse 'sexual difference - was the constitutive condition of feminism as a political movement ${ }^{21}$.

The nature of this research lens will make Cybermind appear more riven by gender than most of its members would probably recognise.

The study of gender online is further complicated by gender behaviours in the West (at least) appearing to be in an almost constant state of flux, interrogation or reinforcement of certainties, and it is not surprising that these interrogations, challenges and reinforcements occur online. As Verena Kuni remarks, "the Net is a contested zone, and... this fact must be part of our awareness as we work on it”22.

\section{A Note on Gender and Performance}

Following Judith Butler it is common to think of gender, or other social categories, as performative, and thus open to relatively easy reinterpretation, particularly online ${ }^{23}$. Thus Sharpe writes, "The virtuality of race in cyberspace begins to expose it as already a virtual construction in real life” and quotes Nakarnura:

\footnotetext{
${ }^{20}$ Jonathan Marshall (2004a) "The Online Body Breaks Out? Asence, Ghosts, Cyborgs, Gender, Polarity and Politics”, Fibreculture Journal, Issue 3. <http://journal.fibreculture.org/issue3/issue3_marshall.html>

21 Joan Wallach Scott Only Paradoxes to Offer: French Feminists and the Rights of Man, Harvard University Press 1996, p 3-4.

22 Verena Kuni “'The Future is Femail' Some Thoughts on the Aesthetics and Politics of Cyberfeminism”, conference paper quoted by Faith Wilding:

$<$ http://www.obn.org/kassel/faith_report1.html>

${ }^{23}$ Judith Butler Bodies that Matter: On the Discursive Limits of 'Sex’, Routledge, NY, 1993.
} 
Performing alternative versions of self and race jams the ideology-machine, and facilitates a desirable opening up of what Judith Butler calls 'the difficult future terrain of community' in cyberspace $(1995)^{24}$.

Butler's ideas stem from an application of the work of J.L. Austin on 'performative statements' to gender ${ }^{25}$. Performative statements or acts are statements or acts in which the correct saying or doing of something, in the correct context, makes something so. The usual examples are marrying a couple, naming a ship, declaring a debt and so on. Austin implies that many supposedly ordinary statements are actually performative rather than denotative, and hence that naming is always somewhat problematic.

The existence of performative acts points to the both the magic and the conjuring inherent in society; in which many things only exist because some people can make these performative statements, and others 'go along with them', or the acts are reiterated, sometimes backed by force, and then become part of the social order itself, and hence of reality. As John Searle points out, there is a whole class of 'facts' like money, weddings, law and so on, which exist only because of humans. Yet if we try acting as if these things are not facts of the same order as 'gravity', say, then we will find them obdurate, accepted in the actions of others, and enforced, whether deliberately or not ${ }^{26}$. These 'facts' cannot be overcome simply by declaring them over, or through subversive performance. This is even more the case online; if a group essentially writes you into existence via their responses in a way which does not correspond to 'you', then 'the facts' become the facts as iterated - you, your being or whatever, cannot be expressed so as to be understood, so you (or your category of people) become negated. This is especially likely if your own speech is hesitant as an outsider in the first place. The negation may then become the fixed way others in that group react to you (providing the consequences are reiterated). Much discourse in the society or group may then concern itself with showing that this magic of immutable social facts is 'rational', and the conjuring is 'real', rather than exploring, or exposing, how it is done.

While there may be no issue with the idea that society is a 'magical act' in this sense, as it ties in with the importance that has already been given to words, rhetoric and

\footnotetext{
${ }^{24}$ Christina Elizabeth Sharpe, "Racialized Fantasies on the Internet”, Signs, 24(4), 1999: 1089-1096, pp.1090, 1095.

25 J.L. Austin How to do things with Words, Oxford University Press, 1962.

26 John Searle Mind Language and Society: Philosophy in the Real World, Weidenfeld \& Nicolson, London, 1999: 112ff.
} 
categories, there is an important ambiguity which cannot be ignored. To make this clearer, let us substitute the term 'affirmative' for Austin's 'performative', in the sense that an affirmative act is an attempt to make something so. An 'affirmation' is such an event. Now a performance, in the standard sense, may not be an affirmation. In fact the performance may be 'bracketed' so that it is not an affirmation. People who get married in a film may not be married in real life, even if they carried out the ritual properly, neither should anyone really die, nor revolutions really occur; the context renders it invalid and is meant to render it invalid. What this distinction between performance and affirmation points to is that performances tend to be automatically bracketed as unreal, otherwise they are not performances.

However, even a marked performance can also be a manifestation of something held to be essentially true, and it should not imply automatic liberated play. An actor or a musician is not entirely free to do as they choose, even if they have no script or score. If they want to achieve particular kinds of results, they have to make use of conventions, even if only to break them. If the performance of the 'other' or 'non-standard' selves is done through cliches and marked symbols, then it may become no more than a customary 'ritual of reversal' and simply reinforce existing power structures ${ }^{27}$. No matter how many selves a person has - they are still subject to control focused on their one body. Similarly iteration may open up opportunities for variance, but it can also reinforce closure, as a ritual - the reiteration, which is recognised - is what makes an affirmation possible.

As communication is always uncertain, people already have social strategies to make sense of events without changing their sense of self or social process. All communication involves active interpretation on the part of the participants, and constant (if possibly contested) efforts to define the context or framing so as to help decode the message. If the framing is largely pre-existing and in harmony with power relations and the ongoing pattern of activities, then events which can be included within it will tend to be interpreted in an orthodox way, no matter what the intention of the participants. People will select bits of both the events and the context to make sense of the acts. Thus subversive performances always have the possibility of being taken to reinforce the framings and the supposed nature of life.

\footnotetext{
${ }^{27}$ Max Gluckman Custom and Conflict in Africa, Blackwell, Oxford, 1960, particularly chapter V.
} 
Thus, it would seem that the idea of performance says little more than that categories and associations, or human 'social facts' can be contested, and that people attempt to make their categories real via socially recognised procedures ${ }^{28}$. The political implication is that it is more radical to make the process of affirmation look artificial, rather than simply engage in performance. None of this is to deny that gender can be such an affirmation, but gender is also being situated in a ground of expectations which validate and impose that affirmation, interpret the emissions from that site of affirmation and limit and enable results, irrespective of intentions of any 'performer" 29 . This is influenced primarily by importation of gender structures from the offline world, which is still dominant in terms of experience.

\section{Gender and Technology}

The relationship between gender and technology is complex, but must be touched on. Briefly most scholars who consider the issue think that some technology is gendered and, in particular in the West, most technology that is considered important is also gendered as masculine ${ }^{30}$, with particular types of male identity, power, sexuality and styles of relating bound up with particular types of technology ${ }^{31}$. As a result, women may not only be forcibly excluded or find the path exceedingly hard or repulsive to travel, but embrace an anti science and technology position to emphasise their identity

\footnotetext{
${ }^{28}$ It should be clear that some of these objections are also influenced by Butler's later work such as Excitable Speech: A Politics of the Performative, Routledge, NY, 1997.

${ }^{29}$ For the use of another term which seems to aim in a similar direction see Candace West \& Don H. Zimmerman “Doing Gender”, Gender and Society, 1(2),1987:125-51.

${ }^{30}$ Obviously this might differ with who is making the judgement, and implies something about the men making the official valuations and the way these views are propagated. David Edgerton instances a poll of the British public, which gave the bicycle as the most significant technological innovation since 1800, followed by the treatment and supply of water, The Shock of the Old, Profile Books, London 2006: 4.
}

${ }^{31}$ Again the arguments are far too complex to go into here. For introductions see Marshall (2007a: 498500), Judy Wajcman Feminism Confronts Technology, Polity Press, Oxford, 1991 and Techno-Feminism, Polity Press, 2004. Zoe Sofia points out that some types of technology can be considered feminine in “Container Technologies", Hypatia, 15(2), 2000:181-201. The argument that technology has only recently become 'masculine' is put forward by Ruth Oldenziel Making Technology Masculine: Men Women and Modern Machines in America, Amsterdam University Press, 1999. Sally Hacker in Pleasure, Power and Technology, Unwin Hyman, Boston 1989, suggests that gender structures the ways in which technology is used for pleasure, the main form of which in a patriarchal society being male (sexual) domination of women and nature. This in turn excludes women from the discourse of technology and participation in its construction. Other theorists further draw attention to how processes of dominating women lead to ideas of using technology to rape and dominate a 'nature' which is associated with women, cf Carolyn Merchant The Death of Nature : Women, Ecology, and the Scientific Revolution, HarperCollins, New York 1980; Val Plumwood Feminism and the Mastery of Nature, Routledge, London 1993. 
as female. The lack of women involved in the creation and design of 'new technology' is often remarked ${ }^{32}$. Furthermore personal electronic communication is in some ways marginal to the communication between male dominated financial, military and other institutions which could be seen as devoted to extending their power. As well as the internet extending the livelihood and contact making possibilities for women and other marginalised groups, it also extends the possibilities of exploitation through contingent and disposable work, and the extension of harassment ${ }^{33}$.

However, although technology may be designed to extend or reinforce existing ways of acting and modes of organisation, while taking gender or racial inequalities for granted, it can also have unintended effects which may provide openings for different social constructions. The actual effect of technology on society may resemble a political struggle more than straightforward determinism might suggest. In general, technology often tends to be approached as if it was determinate and liberating in itself or, on the other hand, as essentially corrupting the relations of humans to each other or the natural world. However, technology provides both augmentations and restrictions. Therefore while the intersection of gender and technology may have certain tendencies, the ultimate outcome of that intersection, in any particular case, may still be uncertain; ambiguities abound even at this level.

One metaphor for the relationship of women to technology which, attempts to express this struggle is that of the cyborg. Wajcman writes: "While many have been drawn to cyberfeminism, it is the cyborg figure that has most strongly fired the feminist imagination” ${ }^{34}$. Volkart claims that:

Whereas feminism claimed the appropriation of new technologies as tools for women's liberation, cyberfeminism promotes both the idea of becoming cyborgian and the pleasures involved in it. In other words... a merging of body and technology takes place. It is the concept of the technological body

\footnotetext{
32 “Ann Pollina, co-director of the Connecticut Girls and Technology Network, [says] 'Overall, in the industry, men outnumber women four to one'” quoted by Karen Stabiner "Where the Girls Aren't”, New York Times, $12^{\text {th }}$ Jan 2003. <http://www.nytimes.com/2003/01/12/edlife/12STABINE.html>. Jane Margolis and Allan Fisher in Unlocking the Clubhouse: Women in Computing, MIT Press, 2002, describe ways in which the number of women in computing courses at Carnegie Mellon was increased.

${ }^{33}$ Wajman (2004: 3-7).

${ }^{34}$ Wacjman (2004: 7). Recently nearly a whole issue of the prestigious journal Theory, Culture and Society was devoted to cyborgs (December 2006, Vol.23, No. 7-8, effectively issue 8)
} 
which is the medium for pleasure and liberation, and not the technological tool itself ${ }^{35}$.

This use of the cyborg descends from the work of Donna Haraway who used the figure to argue against those 1980s back-to-nature-goddess-feminisms that suggest that all technology is inherently corrupting or masculine. Haraway rightly points out that there never has been a 'pure' bounded human, but that we are all technological in some way. In her paper, Haraway argues that the cyborg, “a cybernetic organism, a hybrid of machine and organism” ${ }^{36}$, can be a model for re-imagining liberation.

In the traditions of 'Western' science and politics... - the relation between organism and machine has been a border war. The stakes in the border war have been the territories of production, reproduction, and imagination ${ }^{37}$.

In particular, the borders concerned are those between animal and human, human and machine and physical and non-physical. The cyborg is held to challenge these divisions, without leading us to the "seductive" desire for some kind of "organic wholeness" 38 . By a logic which is never quite explained, nature then ceases to be simply a resource appropriated by or incorporated into (corporate capitalist) culture.

I have argued elsewhere that myths have their own directions irrespective of what people might intend, and that it is by no means clear that the figure of the cyborg or human embedded in machinery can be separated from its patriarchal military origins or its continuing role in corporate economics ${ }^{39}$. The border war may have already been fought and won by the dominant groups extending the machine into the regulation, and incorporation, of the subordinate; in effect making work total, rather than undermining spurious unities. Seeing relatively oppressed groups as active, resistant and not powerless, does not require us to transform either them or ourselves into cyborgs and Haraway later admitted that including third world women working in electronics

\footnotetext{
35 Yvonne Volkart "The Cyberfeminist Fantasy of the Pleasure of the Cyborg” in Claudia Reiche, \& Verena Kuni, (eds) Cyberfeminism. Next Protocols, Autonomedia NY, 2004. Version used at: $<$ http://www.obn.org/reading_room/writings/html/cyberfem_fantasy.html>

36 Donna Haraway “A Cyborg Manifesto: Science, Technology, and Socialist-Feminism in the Late Twentieth Century” in her Simians, Cyborgs and Women: The Reinvention of Nature NY, Routledge 1991: 149-181, p. 149.

${ }^{37}$ Ibid: 150.

38 Ibid: 150.

${ }^{39}$ Marshall (2006: 948-9; 2004a)
} 
factories within the unifying "we" of the cyborg was problematic ${ }^{40}$. There is, at the least, a status difference between a consumerist cyborg and the enforced cyborg, as well as a difference in what they are able to $d o$. Despite the intention to avoid narratives of wholeness, the cyborg is often treated as if one, even though rent with status and class differences. Cyborgs are usually not situated in our social world.

Furthermore, the cyborg is not, as Haraway claimed, without dependency ${ }^{41}$ as cyborgs must depend on machines and servicing, even while these machines may be elsewhere or under the control of others. More to the point, the myth of cyborg is not 'postgendered' as originally claimed (for example, portrayals of cyborgs on the internet tend to be thoroughly gendered), and the cyborg provides little in the way of tools to rethink the way that people actually use gender ${ }^{42}$. Most writings using cyborgs tend to be studies of literature, film, philosophy or even theology, rather than of what people do socially. Even then, Volkart who is an enthusiast, can write "it is obvious that there are not as many hybrid techno figurations, high tech artists, or hackers as one would expect after having read cyberfeminist theories"43. It is of some significance that none of the writers in this journal issue have used that cyborg myth, and that cyborgs were rarely mentioned on Cybermind, and then in general by males ${ }^{44}$.

From the evidence presented in the papers in this Journal it would seem more fruitful for the investigation of gender to keep a focus on the ambiguities, oscillations and tensions around gender and online life, or around the categories and borders which cannot always be bridged, than to risk loosing them through the smoother (or internalised) blendings of an easy hybridity. It is also fair to point out that Haraway herself now claims that "by the end of the millennium, cyborgs could no longer do the work" and she has turned her focus to “companion species” in particular dogs ${ }^{45}$.

${ }^{40}$ Constance Penley and Andrew Ross “Cyborgs at Large: Interview with Donna Haraway” in C. Penley \& A. Ross (ed) Technoculture, University of Minnesota Press, 1991: 12.

${ }^{41}$ Haraway (1991: 151).

42 Danielle DeVoss, "Rereading Cyborg(?) Women: The Visual Rhetoric of Images of Cyborg (and Cyber) Bodies on the World Wide Web”, Cyber-Psychology and Behaviour 3(5) 2000: 835-46. See also Marshall (2006a: 948).

${ }^{43}$ Volkart (2004: np)

${ }^{44}$ Marshall (2007b: 144-5).

45 Donna Haraway The Companion Species Manifesto: Dogs, People and Significant Otherness, Chicago, Prickly Paradigm Press, 2003: 4. 
A variant of this theory, with a more direct social application, comes from the writings of Sadie Plant. Plant not only argues that "women have not merely had a minor part to play in the emergence of digital machines” being historically responsible for design, programming and assembly of such devices ${ }^{46}$, but that through the internet and other global technological changes:

the roundabout circuitous connections with which women have always been associated and the informal networking at which they have excelled now become protocols for everyone ${ }^{47}$

Networks "epitomize the shape of this new distributed nonlinear world" 48 . They are "bottom-up, piecemeal, self-organizing” and emerged "without any centralized control" ${ }^{49}$. As a result, all "individuated notions of organised selves and unified lives are thrown into question” ${ }^{50}$, and the basis of patriarchal power based in linearality and a single united identity is threatened ${ }^{51}$. Perhaps her argument is best explained in this excerpt from an interview:

It just so happens that, for the worst of reasons, women have had very different experiences of identity and subjectivity and the whole notion of the self. This applies even in the most ordinary everyday circumstances; women have always had to do several different things at once, to be far more malleable. Now obviously, in the past, they've had to do that in order to fit around men, or in more philosophical terms, to fit around the phallus, or whatever we want to call the central organizing point of everything. If that central organization begins to be eroded, obviously not just by technology, but it just so happens that that is one place where you can see this happening very clearly, then there is a possibility that the whole culture begins to shift to a mode of organization which is actually more compatible with the ways that women have had to operate in the past ${ }^{52}$.

Again the issue with this theorising is whether or not it is accurate. Do all or most women find networking online inherently liberating? Are most women's identities more

\footnotetext{
${ }^{46}$ Sadie Plant Zeros and Ones: Digital Women and the New Technoculture, London, Fourth Estate, 1997: 37 and passim.

47 Ibid: 144 .

48 Ibid: 46.

49 Ibid: 49.

50 Ibid: 143.

51 Ibid: 45-6, 170, 173ff. Networks "undermine both the world view and the material reality of two thousand years of patriarchal control”, Sadie Plant "On the Matrix: Cyberfeminist Simulations”, in Rob Shields (ed) Cultures of the Internet: Virtual Spaces, Real Histories, Living Bodies, Thousand Oaks, Sage, 1996: 170.

52 “Technically Speaking: An interview with Sadie Plant by Zoey Kroll”:

<http://www.penelopes.org/archives/pages/ntic/newmed/sadie.htm>. Without this interview I would have agreed with Wajcman that Plant's views of gender were both essentialist and contradictory (2004: 73).
} 
easily acted out, dispersed or changed? And does the internet provide many spaces in which gendered power relations are challenged? The answer would seem to be not really, or that at best it is not apparent as yet. Women do not seem, in general, less believing in the single authentic identities of others or less inclined to treat gender as a binary. Nor do they seem inherently happier with uncertainty and ambiguity; often it seems that these ambiguities can increase levels of fear and sensations of harassment. Even if women are central to the network around the List, it is not certain that this destroys male power, anymore than mainly female networks offline usually do in themselves without sustained political struggle. Furthermore, although I cannot recall any woman saying that she found her networking skills made online life easier, several women have made comments to me and to the List which imply that they find it a relief to get out of 'female style' networking. Thus:

certainly i see women form networks and women go out in groups. i might have some problems with this because I always hated these networks. i guess the things most women are interested in i find really boring/stupid - $\mathrm{i}$ know thats a generalization - but its the networks people like my sister-inlaw and my mother have - and i know why they have those networks and if ichose that kind of life i'd probably have them too.

Another woman writes, also within this context:

Oh, you're talking about a *girltalk* list. I have no idea of the social dynamics on those. I don't belong to any; they bore me to death.

One thing that has been clearly demonstrated is that women have moved online in numbers. In the early 90s estimates of the number of women online were very small but this, although it varies from country to country, has now altered, and the ratios approach those of the population at large ${ }^{53}$. Figures given by Pew Internet Project for the USA state for 2005:

$67 \%$ of the adult American population goes online, including $68 \%$ of men and $66 \%$ of women. But women slightly outnumber men in the internet population because they make up a greater share of the overall U.S. population... Younger women are more likely than younger men to be online; older men are more likely than older women to be online.

This Pew research also found that men are still more likely to use the internet more frequently than women:

$61 \%$ of men and $57 \%$ of women go online on a typical day. $44 \%$ of men go online at least several times a day, compared with $39 \%$ of women.

\footnotetext{
${ }^{53}$ Marshall (2007a: 500-501).
} 
Men and women are equally likely to access the internet from home.

Men and women are equally likely to access the internet from work ${ }^{54}$.

Use of the Internet may have become less gendered as it moves into the home and as it requires less technical proficiency to get online than previously. However, issues around distribution of work in the home (part of the inequality arising from association of the female with the private or intimate sphere) and amounts of disposable income, almost certainly affect internet usage, but this is not a matter of technology. There is also some evidence that younger internet users tend to use the internet to communicate primarily with people they already know, and that they tend to consider the internet to be the World Wide Web and email, and rarely use email Lists. However, this does not mean there are not gendered usages. Thus it seems that Western women may use it more to keep in contact with friends and shopping, while most males use it for downloads and joining interest groups ${ }^{55}$. This does not seem to have been the case as reported by people using Cybermind, but obviously the women members were of the type to join a relatively esoteric interest group ${ }^{56}$.

\section{Problems of Research}

The most obvious problem of research is the question of whether we can be sure enough of the identity of people to make statements about their gender. However, this is not really that much of a problem. Firstly, because even when gender is not clear people are usually gendered by themselves or others, and that shows us something about how gender is used. If a person uses a 'non-standard' gender then that still tells us something about the conventions of gender. The objection is only valid if you assume that the relation of gender to biology/sex organs is unproblematic. Secondly, gender impersonation is not common on Mailing Lists, and in particular is not common on

\footnotetext{
${ }^{54}$ Deborah Fallows How Women and Men Use the Internet, Pew Internet and American Life Project, Washington, 2005: 2-3, <http://www.pewinternet.org/pdfs/PIP_Women_and_Men_online.pdf>

Figures for Australia suggest a similar result; see the Information Economy Index 2006, Department of Communications, Information Technology and the Arts, Canberra, 2006: 7, 14. Robyn Greenspan gives figures for Europe which are not as balanced. Thus $46.84 \%$ of people online in Sweden were women, 44.61\% in the UK, and 38.02\% in Italy, "Europe, U.S. on Different Sides of the Gender Divide”, Internet News, October 21, 2003. <http://www.internetnews.com/stats/article.php/3095681>

${ }^{55}$ Fallows (2005: 3-4).

${ }^{56}$ See my paper “Cybermind Discusses Gender” in this journal.
} 
Cybermind $^{57}$. On Mailing Lists, gender can often be read from the address which may give a common male or female name, or because over the course of time people will sign their posts with a common male or female name. Pseudonymous activity is rare on Cybermind (especially among frequent posters), and perhaps on lists in general; whereas on MOO, pseudonyms are standard and email addresses are usually hidden. All the Mailing Lists, of which I have experience, tend to be places in which people attempt to manifest their 'real identity', rather than 'play with', or hide, identities. An experimental attempt to start up a list of Cybermind members in which people appeared anonymously with no specified gender had a very short life. That is not to say that cases of gender unclarity did not arise, but these seem to have been unintended, and arose largely because of the conventional modes of reading gender deployed by others. Furthermore, gender ambiguity only seems to be a problem when it is a male impersonating a female, and not the other way around ${ }^{58}$.

Thirdly, this ambiguity is fundamental to online life as are many other kinds of ambiguity. It is not something which can ever be resolved completely. I have argued elsewhere that internet communication evokes an existential anxiety in people from Western English speaking countries, as one’s existence online is uncertain and depends upon the response of others. Status, recognition and presence are forever slipping out of sight. I have called this type of existence, hovering between presence and absence asence $^{59}$. In this sense, flame wars are methods of resolving asence, as is netsex, and the constant attempts to check up on others who become important and to uncover 'their truth'. It means that the writing of others can define one. Sondheim points to something similar with his idea of 'rewrite" ${ }^{60}$.

\footnotetext{
${ }^{57}$ See my paper "Cybermind Discusses Gender” in this collection, and for a summary of the similar results of other research see Marshall (2006a: 932-6). In my experience, Mailing Lists tend to have less general anonymity and identity role-playing than is the case on MOOs, newsgroups or IRC for example.

58 This is also discussed in more detail in the paper "Cybermind discusses gender" in this journal. It is apparently the case for Chinese gamers as well, see Weihua Wu et al, "Beyond Virtual Carnival and Masquerade: In-Game Marriage on the Chinese Internet”, Games and Culture, 2(1), 2007: 59-89, p 7881.

59 Marshall (2007b: 89-92 and passim), and "Governance, Structure and Existence: Authenticity, Rhetoric, Race and Gender on an Internet Mailing List”, Proceedings of The Australian Electronic Governance Conference 2004, Centre for Public Policy, University of Melbourne (2004b).

$<$ http://www.public-policy.unimelb.edu.au/egovernance/papers/21_Marshall.pdf>

${ }^{60}$ in "From the Internet Text" this Journal issue
} 
Even if this gender vagueness is the case, then it does not mean that assumptions about gender are challenged. As Lori Kendall writes: “choosing one gender or another does nothing to change the expectations attached to particular gender identifications" ${ }^{\text {61 }}$. The clichés about gender may even become stronger, when there is no visible sex/gender to correct them ${ }^{62}$.

Another more significant problem arises from the possibility that if there is an official discourse and it is associated with gender then it may be likely that many of those who belong to the 'other' gender do not have the language in which their experiences can be portrayed, and thus appear inarticulate and unrepresentable. This may particularly be the case if their social roles are comparatively undefined, or hidden, or do not correspond with the view of reality enunciated by the dominant group ${ }^{63}$. As a result, questions of what they believe etc. cannot be resolved by quoting their own words, and may tend to be discounted by ethnographers as unimportant. It may also be the case that cultural rituals act to make the person more overtly incomplete, mutually dependent and unable to articulate because of this incompleteness. This is already suggested by the way the gender binary can act to invalidate parts of a person ${ }^{64}$.

There is no answer to these problems other than to recognise that inarticulate experiences are part of human life, to be sensitive to such moments, and to attempt to define the kinds of situations in which they appear. There is also no real reason to think that this only happens to the disempowered. The dominant group may also not be able to describe situations accurately, or consider them important, when they are perfectly 'speakable' by other groups in society. This may especially arise if the basis of their dominance is under challenge and the only speech they have is abuse or threat, or to loudly pretend nothing is happening. In this study, it does appear that moments of discomfort are common and gendered. Some women do express the feeling to the List and sometimes to me that something is wrong or unpleasant, but that they do not quite

\footnotetext{
${ }^{61}$ Kendall, Lori (1996) "MUDder? I Hardly Know ‘Er! Adventures of a feminist MUDder” in L. Chernny \& E.R. Weise, E.R. (eds) Wired Women, Seal Press, Seattle 1996: 217.

${ }^{62}$ See the introduction to Esther Milne's paper in this collection.

${ }^{63}$ See Edwin Ardener "Belief and the Problem of Women" and "The Problem revisited", and Shirley Ardener "Introduction" in Shirley Ardener (ed.) Perceiving women, Malaby Press, London, 1975: 1-27, vii-xxiii.

${ }^{64}$ Marilyn Strathern "Making Incomplete" in Vigdis Broch-Due, Tone Bleie, and Ingrid Rudie (eds) Carved Flesh, Cast Selves, Berg, London 1993: 41-51.
} 
have the words to express it. Thus, for example one female List member wrote to me, showing my failing on precisely these issues:

I guess what angers me (and yes, there's a difference between us, whereas you talk about discriminatory practices dispassionately and disinterestedly, speaking in the voice of reason and scientific authority, (a problematic stance for some), no matter how hard I try, I confess, the history of women's servitude is one that angers me and spurs me into action. One aside leads me to a second--is this what Irigaray calls women's "babbling" ;)? I wonder if our approaches to these questions are really gendered; I'm beginning to think that they are, and that we're speaking a different language. I speak from the heart, taking the side of individual women, while you are looking at matters through the telescope of a whole culture. Whereas you have a bird's eye view, I chose the worm's.

\section{The Papers}

This introduction is the first refereed paper, but the other refereed papers in alphabetical order by author, are as follows.

Using an approach originating in 'Critical Discourse Analysis', Alexanne Don looks at the ways the language of gender is inflected by people's orientation towards both 'addressivity' and 'orientation towards response', and how gender is significant in negotiation over moral order and in bringing forward what is important to discuss. The first part of the paper discusses how language is not disembodied and can be used to police and set norms, while the second part of the paper takes a statistical look at two short strips of activity on Cybermind, and shows that issues of gender are complicated by issues of poster prominence. Lower rates of participation result in lower rates of response and address to female posters. However, female posters seem to orient themselves more directly to the people they are responding to than the male respondents do. Males are more likely to initiate topics, and when they do respond, are less likely to address their respondees directly, preferring to address the audience in general, or to 'claim the topic' for themselves.

Jon Marshall takes a descriptive ethnographic approach to describe how competing categories of race and gender were deployed in a dispute on the List, showing how the category of race functioned as a mode of division, but that categories of gender and gendered behaviour were able to function as modes of unification. These categories, although depending on their shape and deployment in the offline world, took their final values during the course of the dispute. Marshall further points to the ways that people 
contested expertise, and exploited category membership in order to give their words worth. He suggests that rather than considering the group to a have a fixed 'culture', or a culture lying in wait to manifest, it is perhaps more accurate to think of culture as contingent upon histories and as subject to dispute. The results perhaps could have been different, but in either case the resultant group culture would not have been independent of race or gender categories. While it could be argued that despite occasional ambiguities men and women do form mutually exclusive categories, race is very much a shifting scale being forced into a binary, yet the exclusions appear to be more forceful as a result. It is possible that binary social self categories create incompletions which can either be 'integrative' or 'dispersive'. In either case the categories create differences, which then have the potential to increase.

Esther Milne uses a cultural theory/critical internet studies approach, to explore a series of incidents she witnessed on Cybermind in which the List Owner's fictional characters were appropriated by another person. Gender enters into the appropriation through the genders of the main players and through the gender of the characters involved. These factors lend extra power and presence both to the initial writing and to the appropriation. As Milne points out, there is no trace of the 'free play of selves' which was hoped for in early internet theory. Even within impersonation and identity games the user's subjectivity appears to remain relatively stable and connected with theories about 'rights' to 'own' writing and self image and in this case to an associated aesthetics. Milne writes:

Without a faith in the capacity for written communication to make present an author's emotions, creativity and political beliefs, identity - whether multiple or singular - could not be realised through email communication.

So, conventions of authenticity are already assumed. Thus it seems, that even in a situation where people theorise pointedly about the indeterminacy of the text and signage generally, they not only wish to retain the meaning they intended, or not have other meanings associated with them, but they assume they can read the texts of others easily and that those texts have little ambiguity and much immediacy.

Dierdre Ruane takes a more historical approach to investigate how attitudes towards gender and gender behaviour have changed in the last ten years, and compares Cybermind with both a women's and men's community on Livejournal. She concludes that there have been some changes, such as women engaging more openly in adversarial 
debate, being less likely to hide their gender, and she notes the appearance of the possibility of non-binary genders, but the binary relationship between the categories still remains dominant. It also seems that women have a more active role in the generation, and performance, of their perceived gender as female, which might still suggest that the default gender is still male despite the changes in population balance.

In the unrefereed 'Reflections' section, again proceeding alphabetically, we have:

Elizabeth Barrette exploring, in a short poem, the paradox around her gender: that some things are true but not real while some things are real but not true.

B. Dorris explores the ways that her encounter with sex-spam and with internet based behaviour and discussion on Lambda MOO and Cybermind, led her to realise that men are not that strong or certain about themselves, and that as a woman she had more power than she had thought. If indeed, power differentials are shown by which group worries most about the other, then perhaps the worry and defensiveness that may be being shown by men is a sign that gender relations are changing. However, while the internet allows a quicker evaluation of intimacy, women can be still constrained by a fear of violence and the uncertainty about what men might do to them. Online relationships between men and women play out largely as a result of male insecurity and female fear.

Salwa Ghaly describes her experiences on Cybermind and elsewhere. She argues that women can experience the List as a space holding out a liberatory promise yet still have people working to align 'disembodied' with 'embodied' space. This is explored through considering how gender both frames conflict and the language of conflict, how gender can be a subject of conflict, how intimacy can develop offlist, and through taking into account the problems of sustaining an online 'community'. Ghaly also suggests that individuals can make a huge difference in the hospitality of an internet space to women and others in general, and briefly discusses how the List has changed over the years, especially after the War in Iraq.

Jon Marshall provides illustrations, which develop themes begun in this introduction, by summarising and discussing various events on Cybermind and giving the reflections of 
people on the List on the problems that we have considered here. In part this includes the kinds of things/events that make people aware of gender, the attitudes to gender and communication, the problems of gender ambiguity, relations between gender and politics and brief consideration of bodies and netsex.

Caitlin Martin discusses her experiences as a 'girl gamer' on various large scale computerised role playing games, and the ways that gender influences behaviour towards her in those games and at work. This is the only paper which does not consider Cybermind, but it is included for its general interest.

Alan Sondheim, the List founder, contributes a short description of his work as it touches issues of gender. This is followed by some excerpts from the early part of his Internet Text, which introduce some of his key themes such as 'rewrite', 'third sex', and 'hysteria'. The actual internet text is at least twenty megabytes long. It is a constantly developing, self-morphing fantasia, or fugue, on certain key terms; it wanders and oozes between philosophy, poetry, aphorism and play of sign. Hopefully the selections will stimulate some uncertainties in the reader about the problems that the internet can open for philosophy and subjectivity, and lead to people wandering through the main text.

\section{Summary of Results}

It is useful to give a brief summary of the results of the project.

1) Gender was used to resolve ambiguities of communication and expectation.

2) Gender was important in the separation of areas or 'locales' which are constituted as personal from those constituted as public. Personal areas tend to be associated with women and public with men. Due to this division, public power relations tend to be seen as masculine with women more active in personal email communication around the group. Prolonged 'private' email communications generally seem to have at least one woman involved. In general, discovery of the 'authentic identity' of others becomes more important as those involved head towards intimacy, as conventions of authenticity and intimacy involve gender. 
3) The structures of communication which define the online forum as a Mailing List, or as a MOO or website etc, lead to different potentials for behaviour. In particular, they affect the uses and relevance of gender by changing the zones definable as public and private and the ways that people go about meeting in them and acting across them. Thus behaviour on a List, a newsgroup, or a MOO can be 'spontaneously organised' in different ways. Divisions between public and private also shift depending on contexts, but are usually treated as absolute, which can generate further ambiguities. Websites, for example, mark an ambiguous zone. They can be seen as public displays marking the owner's gender for the public world, or they can be seen as private, even verging on intimate ${ }^{65}$. These aims can conflict, especially for women because of their marked private role, and because the default public gender is male. Thus establishing that a person is not male often requires the site to be marked as female, which they may feel takes away from the presentation of a more complex truth about themselves ${ }^{66}$.

4) It was found that even with no attempt to impose a masculine hegemony, or even with active attempts to avoid this hegemony, online life tends to reinforce it. Women often seemed to feel that the default gender was male, so to be true to themselves they often had to mark their 'femininity' artificially, even in women only groups. Ultimately overt obvious power seemed to be retained by males, who tended to have the time to achieve positions of structural power, such as becoming moderator ${ }^{67}$.

5) While the proposition that women would not engage in conflict online was manifestly false (although women seem more likely to flame other women than to flame men), it played an important part in maintaining the symbolic and organisational association of women with intimacy and relationship. Women who display anger readily, make themselves outsiders more easily than would men engaging in similar behaviours. Women also seem more likely to respond to attacks by withdrawal. Strict

\footnotetext{
65 Thus researchers often claim the division is clear even when research subjects disagree. Without a willingness to accept complexity, online research will become increasingly resisted and disruptive for users.

66 There is little in the way of study of unconscious effects on gendered web presentation, but a recent work states that "male professors from German universities and male politicians of the German parliament are shown with significantly more facial prominence than female professors and female politicians" and that this is been common offline as well and expresses status differential. Ursula Szillis, Dagmar Stahlberg "The Face-ism Effect in the Internet Differences in Facial Prominence of Women and Men” International Journal of Internet Science 2 (1) 2007: 3-11, p7..

${ }^{67}$ For most of its existence Cybermind has had male moderators, but this has not always been the case.
} 
moderation can lessen the effects of flame but, as flame is evaluated subjectively and in terms of both the category membership of the person emitting the message and the person evaluating the message, established in-group members will be cautioned less than out-group members; and discussion about whether a message-item was a flame can undermine the order the moderator is trying to impose.

6) Flame wars tended to cluster around external world fractures (such as politics, gender, race, nationality and so on), which were then used to interpret what was going on, or what people were writing. These interpretations did not always seem relevant to what people were trying to say. External world identity factors often overpower any sense of identity as an Internet grouping - perhaps because it is hard to act as an Internet group in relation to other such groups.

7) The loudest and most persistent people in the group define the atmosphere/mood of the group which in turn influenced the kinds of people who joined in, or persisted with the group. Thus groups which have numerically predominant male posters, will have their culture defined by males. Effects lessen the more women participate. Thus, in a feedback loop, the more that some women participate, gaining have high status through that participation, the more that other women will be able to join in; especially if the high status women respond to them. Cybermind, in its heyday, had many active high status women, who self-consciously encouraged women to participate, and who defended other women against what they perceived as sexism. This was probably helped by the generally 'liberal-left' political trend on the List in which 'sexism' was generally recognised as a 'bad thing' with little status generating power (although perhaps not when a person, as a male, was committing it). This relatively accepting atmosphere did not end gender roles and it seemed that 'unconscious' sexism was rarely admitted to.

8) On Cybermind, it seemed that women usually performed the 'emotional labour' which helped group, or community functioning. However, what evidence there is suggests that most of this work was conducted offlist, in private with little public recognition or status awarded. Therefore, those not involved were rarely aware of what was going on, or of the importance of an essential part of List life. 
9) As messages count as exchange, even if male and female members produce different kinds of messages, then there is possibility for exchange to be felt to be relatively equal, as personal contact needs exchange as much as public contact does. In other words it is possible to see that the economy of the List would be able to move towards equitable difference in theory. This will be affected by how much offlist interaction there is between those who are visible on List.

10) Status generally corresponds to the amount of messages which a person sends to a List, and which gain responses. People who are unwelcome because of their volume will often be told to leave, or to post less, by other members. Thus the atmosphere of the List tends to be defined by those who have the most status, and this again goes back to point number Seven.

11) Offline gender frictions are brought online with the importation of the body, and its place in the offline world, as a guarantor of the truth of what people 'say'. This body includes gender and its symbolic associations. Therefore, it is not easier to overcome gender problems online than offline as users seek to learn the gender of others to discover their truth, or the truth of what they write.

12) Modes of organising internet life often seem disruptive of that order, or to generate paradoxes. Some of these paradoxes stem from 'asence'. Nothing marks the person's actual presence; even an avatar will not indicate whether a person is listening at that moment. This is true for both audience and speaker. Thus expected support and response can be missing, status has to be continually earned as it fades away, people's words can be taken to mean what they had not intended. These processes leave people feeling powerless or burnt out. The self has to be continually rewritten. People can never simply be present together, and online collaboration needs a lot of offline reinforcement, or for someone to take responsibility for making the presence of the group and the activity seem real. Asence may lead to gendered characteristics being exaggerated to convey the truth of the person, while at the same time the exaggeration is perceived to diminish truth. People are always aware of the possibilities of deceit, and these fears are easily triggered. The search for truth intensifies if relationships become closer. If, as is often claimed, you can only be who you really are online, then convention still dictates that this reality has to be verified offline, setting up conflicts. 
Likewise, attempts to build community and closeness by personal off-topic mails can swamp a List causing people to leave and so on. These ambiguities, contradictions and paradoxes need to be explored in research rather than foreclosed or ignored. Online and Offline roles and activities interact in complex ways and it is important to recognise gender as a structuring principle, and as a destabilising principle, of social action on online forums.

13) Fragmentation of List members, and the difficulties of forming sub-groups lead to the position in which power ratios are complex and individually based. It is extremely difficult for any one group or person (perhaps excluding the moderator) to exert dominant power on the List. This means, both that women, or any other social category, are unlikely to be explicitly subdued, but also that they are unlikely to be able to force the List to behave in an equitable manner. The only ultimate sanction is for people to abandon the List and effectively destroy it, or its ability to accommodate difference.

Further research is suggested by the papers in the journal. Thus more needs to be done to explore the ways that people address each other, the kinds of responses that are generated and their relation to the construction of, and power in, gender. We need further research into the ways that people use and appear to 'need' the authenticity and truth that is supposedly expressed by gender categories, and into the ways that different identity categories appear to intersect with one another becoming moments of splitting or of integration. We perhaps need to explore how it is that rhetoric is used to establish culture and dominance, and to see how this is related to the use of categories and knowledges offline. Historically, we need to see how gender is changing in its use online, if it is changing, and how young people treat gender, so that we can attempt to catch the process of social change and/or reaction. We need to investigate how the 'new structures of communication' found in web based forums like LiveJournal, Facebook, and MySpace interact with gender and compare with the more established modes of internet grouping. What are the intersecting roles of network and hierarchy? What part does fear play in reinforcing gender? Does a quest for conceptual certainty about 'the other' really take its force, because of the ambiguity and uncertainty constantly present in Internet life, or is this just a moment in Internet history and culture dependent upon the particular people who were first online in numbers? Will it be overcome, or does it depend on something shared in offline Western Culture? It seems probable that any 
revolution in gender relations online will only happen if it is integrated into an offline cultural movement, which is in some ways primary.

This leads to our final assertion. In order to say anything about gender as it affects online life, we now need to move into an exploration of the way that gender is used and manifests in non-western, non-English speaking, groups and we look forward to a growing amount of work dealing with these issues. One of the central questions will be whether the experience of the different gender expectations of people from other cultures will further affect people's conceptions of gender, or whether people will deal with that difference by moving into partially-bounded and separate groups in which their expectations about gender will be confirmed.

\section{Bibliography}

Ardener, Edwin (1975) "Belief and the Problem of Women" and "The Problem revisited”, in Shirley Ardener (ed.) Perceiving women, Malaby Press, London, 1975: 1-27.

Ardener, Shirley (1975) "Introduction" to Shirley Ardener (ed.) Perceiving women, Malaby Press, London, 1975: vii-xxiii.

Austin, J.L. (1962) How to do things with Words, Oxford University Press.

Butler, Judith (1993) Bodies that Matter: On the Discursive Limits of 'Sex', Routledge, NY.

(1997) Excitable Speech: A Politics of the Performative, Routledge, NY.

Butler, Judith \& Braidotti, R. "Feminism by any other name”, differences: A Journal of Feminist Cultural Studies, 6(2-3) 1994: 27-35.

Connell, R.W. (2002) Gender, Polity Press, Oxford.

DeVoss, Danielle (2000) "Rereading Cyborg(?) Women: The Visual Rhetoric of Images of Cyborg (and Cyber) Bodies on the World Wide Web”, Cyber-Psychology and Behaviour 3(5): 835-46.

Edgerton, David (2006) The Shock of the Old, Profile Books, London.

Elias, Norbert (1978) What is Sociology?, Columbia UP.

Fallows, Deborah (2005) How Women and Men Use the Internet, Pew Internet and American Life Project, Washington. $<$ http://www.pewinternet.org/pdfs/PIP_Women_and_Men_online.pdf $>$ [Accessed 17 December 2007]

Gluckman, Max (1960) Custom and Conflict in Africa, Blackwell, Oxford.

Greenspan, Robyn "Europe, U.S. on Different Sides of the Gender Divide”, Internet News, October 21, 2003.

$<$ http://www.internetnews.com/stats/article.php/3095681>

[Accessed 17 December 2007] 
Hacker, Sally (1989) Pleasure, Power and Technology, Unwin Hyman, Boston.

Haraway, Donna (1991) “A Cyborg Manifesto: Science, Technology, and SocialistFeminism in the Late Twentieth Century" in her Simians, Cyborgs and Women: The Reinvention of Nature NY, Routledge.

(2003) The Companion Species Manifesto: Dogs, People and Significant Otherness, Chicago, Prickly Paradigm Press.

Information Economy Index 2006, Department of Communications, Information Technology and the Arts, Canberra.

$<$ http://www.dbcde.gov.au/_data/assets/file/41073/IE_INDEX_2006.rtf>

[Accessed 17 December 2007]

Kaplan, Lousie J. (1991) Female Perversions, Pandora, London.

Kendall, Lori (1996) "MUDder? I Hardly Know 'Er! Adventures of a feminist MUDder" in L. Chernny \& E.R. Weise, E.R. (eds) Wired Women, Seal Press, Seattle 1996

Kroll, Zoe (nd) “Technically Speaking: An interview with Sadie Plant”. $<$ http://www.penelopes.org/archives/pages/ntic/newmed/sadie.htm> [Access 17 December 2007]

Lorber, Judith (1994) Paradoxes of Gender, Yale UP.

Margolis, Jane \& Fisher, Allan (2002) Unlocking the Clubhouse: Women in Computing, MIT Press.

Marshall, Jonathan (2004a) "The Online Body Breaks Out? Asence, Ghosts, Cyborgs, Gender, Polarity and Politics”, Fibreculture Journal, Issue 3.

$<$ http://journal.fibreculture.org/issue3/issue3_marshall.html>

[Acessed 17 December 2007]

(2004b) "Governance, Structure and Existence: Authenticity, Rhetoric, Race and Gender on an Internet Mailing List", Proceedings of The Australian Electronic Governance Conference 2004, Centre for Public Policy, University of Melbourne. $<$ http://www.public-policy.unimelb.edu.au/egovernance/papers/21_Marshall.pdf> [Accessed 17 December 2007]

(2006a) “Online Life and Gender Dynamics”, “Online Life and Gender Vagueness and Impersonation”, “Online Life and Netsex or Cybersex", and "Online Life and Online Bodies”, in Elieen M Trauth (ed) Encyclopedia of Gender and Information Technology, Idea Group, NY: 926-51.

(2006b) “Categories, Gender and Online Community”, E-Learning, 3(2) $<$ http://www.wwwords.co.uk/elea/content/pdfs/3/issue3_2.asp\#10> [Accessed 17 December 2007]

(2007a) "Gender in Online Communications” in D. Leu, M. Knobel, C. Lankshear, \& J. Coiro (Eds.), Handbook of Research on New Literacies, Erlbaum: 495-523.

(2007b) Living on Cybermind: Categories, Communication and Control, Peter Lang, NY.

Mascia-Leas, Frances E. \& Johnson Black, Nancy (2000) Gender and Anthropology, Waveland Press, Illinois.

Merchant, Carolyn (1980) The Death of Nature: Women, Ecology, and the Scientific Revolution, HarperCollins, New York. 
Nanda, Serena (1999) Gender Diversity: Crosscultural Variations, Waveland Press, Illinois.

Oldenziel, Ruth (1999) Making Technology Masculine: Men Women and Modern Machines in America, Amsterdam University Press.

Penley, Constance \& Ross, Andrew (1991) “Cyborgs at Large: Interview with Donna Haraway” in C. Penley \& A. Ross (ed) Technoculture, University of Minnesota Press.

Plant, Sadie (1996) “On the Matrix: Cyberfeminist Simulations”, in Rob Shields (ed) Cultures of the Internet: Virtual Spaces, Real Histories, Living Bodies, Thousand Oaks, Sage, 1996

(1997) Zeros and Ones: Digital Women and the New Technoculture, London, Fourth Estate.

Plumwood, Val (1993) Feminism and the Mastery of Nature, Routledge, London.

Reeves, Byron \& Nass, Clifford (1996) The Media Equation: How People Treat Computers, Television and New Media Like Real People and Places, Cambridge University Press.

Rosaldo, Michelle (1980) "The Use and Abuse of Anthropology: Reflections on Feminism and Cross-Cultural Understanding”, Signs 5(3): 389-417

Scott, Joan Wallach (1996) Only Paradoxes to Offer: French Feminists and the Rights of Man, Harvard University Press.

Searle, John (1999) Mind Language and Society: Philosophy in the Real World, Weidenfeld \& Nicolson, London.

Sharpe, C.E. (1999) “Racialized Fantasies on the Internet”, Signs, 24(4): 1089-1096

Sofia, Zoe (2000) “Container Technologies” Hypatia, 15(2): 181-201.

Stabiner, Karen (2003) “Where the Girls Aren't”, New York Times, $12^{\text {th }}$ Jan 2003. $<$ http://www.nytimes.com/2003/01/12/edlife/12STABINE.html> [Accessed 17 December 2007]

Strathern, Marilyn (1993) "Making Incomplete” in Vigdis Broch-Due, Tone Bleie, and Ingrid Rudie (eds) Carved Flesh, Cast Selves, Berg, London 1993: 41-51

Szillis, U. \& Stahlberg, D. (2007) “The Face-ism Effect in the Internet Differences in Facial Prominence of Women and Men” International Journal of Internet Science 2 (1): 3-11,

Triebel, Annette (2001) "The Changing Balance of Power between Men and Women: A Figurational Study of the Public and Private Spheres in Western Society” in Thomas Salumets (ed.) Norbert Elias and Human Interdependencies, McGillQueens University Press, Quebec: 175-90.

Volkart, Yvonne (2004) "The Cyberfeminist Fantasy of the Pleasure of the Cyborg” in Claudia Reiche, \& Verena Kuni, (eds) Cyberfeminism. Next Protocols, Autonomedia NY, 2004. Version used found at: <http://www.obn.org/reading_room/writings/html/cyberfem_fantasy.html> [Accessed 17 December 2007]

Wajcman, Judy (1991) Feminism Confronts Technology, Polity Press, Oxford. (2004) Techno-Feminism, Polity Press, Oxford. 
West, Candace \& Zimmerman, Don H. (1987) “Doing Gender”, Gender and Society, $1(2): 125-51$.

Whyte, Martin K. (1978) The Status of Women in Preindustrial Societies, Princeton University Press.

Wilding, Faith “Cyberfeminist International, Conference Report” $<$ http://www.obn.org/kassel/faith_report1.html>

[Accessed 17 December 2007]

Wu, W., Fore, S., Wang, X. \& Ho, P.S.Y. (2007) "Beyond Virtual Carnival and Masquerade: In-Game Marriage on the Chinese Internet", Games and Culture, 2(1): 59-89. 